\title{
A Comparative Analysis of the Entrance of the Safavid Mosques in Tabriz
}

\author{
Nazila Edrisi Khosroshahi ${ }^{1 *}$ and Jafar Giyasi ${ }^{2}$ \\ ${ }^{1}$ Azerbaijan Architecture and Construction University, Baku, Azerbaijan \\ ${ }^{2}$ Azerbaijan National Academy of Sciences, Baku, Azerbaijan
}

Received: 12/04/2020

Accepted: 22/08/2020

Published: 20/09/2020

\begin{abstract}
In fact, the entrances are part of the mosques that cut people off from the outside space and join them to the spiritual atmosphere. Besides, throughout the indirect entrance, an individual can prepare its thoughts and soul to connect to special spiritual environment. This essential traits of entrance reveals its conceptual connection. The present study develops a descriptive-analytical and comparative interpretation and tries to provide an answer to the question of similarities and differences of facade of Saheb Ol-Amr, Zahiriyeh, Maghsoudiyeh Square and Haj Safar Ali mosques in the Safavid period in Tabriz. To provide an optimal structure for facade design, the three factors of entrance shape, the elements of entrance and the components of the entrance were employed in this comparison. The results show the similarities and reveal major differences among these mosques. Additionally, pairwise analysis performed with Expert choice software draws the importance of each factors considered in facade design. The shape of entrance has the ratio of $36 \%$, the following proportions are occupied by components of entrance (35\%) and elements of the facades with the coefficient of $31 \%$. Each parameter provides various suggestions. The shape and elements of entrance, draw Saheb Al Amr Mosque in the first place. On the other hand, Haj Safar Ali assesses the first location from the components' suggestions. While, Saheb Al Amr Mosque has been achieved the third place from this point of view. Both numerical and statistical analysis recommends that Saheb-Ol Amr mosque is the most well-known mosque among the other mosques in the study.
\end{abstract}

Keywords: Mosques, Islamic Architectures, Safavid Period, Entrance, Façade

\section{Introduction}

Mosques have undertaken a design of Islamic buildings. Actually, Islamic art is still discernible from mosques. Also, this structure has been explored as the most important place for engagement of Islamic art and architecture simultaneously [8]. Muslims were first pioneered in mosque designs and had extended and developed the shape and perspectives. In fact, mosques can be determined as an Islamic structure. Also, they focus on visual perception to emphasize the dynamic interplay of whole Islamic architecture [4]. Since, it is better to have a closer look to the analysis of this architectural beauty and remind the ascetic simplicity of worships defined by Prophet Muhammad (PBUH). Mosques are usually being transformed as form or organized structures not only the symbol of a balance of art diversity and religion, but also have tendencies to perceive visual data in configurational terms and see some elements like tiling, brickwork, Mogharnas, cornices, calligraphy, landscaping and some others in such a way that appear to continue each other. The appearance of symbols which is determined by art elements in mosque designs leads us to examine the intrinsic idea of the employed elements. The geometric technique of construction seems to simplify the spiritual environments. The infinite rotation of arcs and columns appears repeatedly in some part of the building, divides this continuous space to identical pieces and lets individuals to "ensemble effect of beauty" and investidoors its roots. This relationship is explored through the application of some of the fundamental structural principles inside this style

Corresponding author: Nazila Edrisi Khosroshahi, Azerbaijan Architecture and Construction University, Baku, Azerbaijan. E-mail: naziedrisi7@gmail.com
[17]. Arguably, the entrance plays an essential role in the attempt to make the visual creation as perfect as possible in the urban and built -on environment.

At the first glance, there is no true variations in mosque entrance figures before the Safavid period. In this period, such massive changes were occurred in entrance architecture. Analyzing and detailed investigation of entrance designing in some of famous buildings in the Safavid period, can suggest and provide an aesthetic dimension of inherent innovation and understanding of architects in this period. In other words, emphasizing the entrance designs as a manifest of this period, the means and far-fetched imagination and designing can be extracted and evoked. Both simple and complex design of entrance in this period follows some architectural rules and are concerned with the combination of the various elements. What is intriguing is that these characteristics can build a comparative and analytical resolution in fields of visual and spatial quality, the interaction of inside and outside and the dimensioning of the Qibla and etc.

\section{Literature Review}

To foster a better understanding of the evaluation of entrance designs in these mosques, we undertook an analysis of earlier researches. Maryam Khazayi in 2015 in her doctoral thesis named as "The influence of Timurid architecture on Mongol and Safavid mosques in India" intended into great detail how Timurid art and designs effect on Mongol and Safavid mosques in India"[5]. Analyzing the courtyard proportion of the Safavid period mosques in Isfahan were elaborated by Attarian et.al (1393). The study showed that in the identification of yard's dimensions (length and width) the section 1.118 was defined. Furthermore, the dimensions 
preserved Iranian module. It is disputable that the yard's dimensions do not exactly match the to 1.118 . Evidence emonstrated that with a tiny error of maximum (one meter) the dimensions can catch this ratio. The source of this error may refer to the amount of mortar between materials or the reformation of the construction [2]. Vaezzadeh Asadi et.al (1393) reviewed the essential factors can assist and simplify the formation of spiritual sense in mosques. The authors concluded that there are many items impresses the creation of this sense. The factors are listed as color, form, decorations and materials. Also some human characteristics like age, level of education can impact the invention of this spiritual sense. Pourmand et.al (1393) argued about the facades of mosques in Isfahan. The sample mosques are Sheikh-Lotf -O-Allah, Abbasi Grand mosque, Hakim and Chahar Bagh. Their study was titled and published as "The comparative study of proportions of facades in sample mosques in Isfahan". The authors explained that the employed proportions of facades not only appear as an intriguing tools but also instance such innovative and master structures. The importance of facades as an urban element in Safavid period, leads to employing specified proportions. Apart from function and importance of facades, there exist some differences in proportions. With reference to results, Abbasi Grand mosque consists of distinct proportion in its design, since the three mentioned mosques show similarities to the proportions employed in their facades. The reason for this challenge is related to its architecture. The rectangular Attitude in Abbasi Grand mosque is derived from the proportion of a Pentagon. On the other hand, the rest of mosques carries out the proportion of the Hexagon [11]. Ramazan Jamaat and Neyestani(1389) has explore the entrance of residential houses in Tehran. The rapid review of entrance researches addresses valuable information. Also, the present study has been greatly echoed the finding. With the aim of principle and axioms of architecture, this paper details and analyses the entrance configuration and design in Safavid period's mosques in Tabriz [13].

\section{Methodology}

The research procedure of this paper is descriptive and analytical. Also it matches comparative approaches. The method of collecting data is of library- type. The field study has been implemented by observing four mosques from Safavid period in Tabriz. The research initiated by combined methodology suggest the greatest convergence between two approaches or more. In this model, researchers apply the various aspects of two different strategies in terms of comparative sections. Besides, the importance of sections can be considered approximately equal.

\section{The Description of Mosque Entrance Construction \\ 4.1 Safavid Architecture \\ The Safavid period has been met many ups and downs} based on the grounds of different reasons. The first one traced back to King's attention, attraction and interest in art and architecture. The next one involves the prince competence in governing [10]. The Safavid architecture commenced to develop in King Abbas period (1589-1627). He established an alternative trend in Islamic architecture in Iran. His fashion and transformation could link his ancestors' rich, precise, sensitive, ambitious and imaginary details to an infinite and meaningful groups of scale and glory. Obviously, this transition not only emerged such an innovation but also reformed and rebuilt the unique and fabulous era in Iranian architecture. This era draws the peak point and examines the final expression in Iranian Islamic architecture [9], [16]. It should be recognized that the architecture features especially public buildings were guided with a global power in this era. However, that is not the first time the features lie behind a political power in Iran. Actually, the public structures observed political schemes in the first years of establishment. The most particular aspect of the Safavid era is the existence of political elements accompanied with identity and personality [12].

\subsection{Functional properties of the Safavid period}

- Throughout urban planning, the cities were growing and developing sharply.

- The mosques and main palace were surrounded with large square shapes.

- Modern complex buildings such as Sacral and open structures.

- Simple designs in most of buildings with more square or rectangular shapes.

- Employing simple geometry, linear and piecewise forms

- Applying the same material and measures for a construction a feature [8]

\subsection{Structural properties of the Safavid period}

- Lack of the time along with the reduction of experienced skilled architecture leaded to low quality and inconstancy in designed buildings.

- Employing various types of domes, for example AlSheikh and Chahar Bagh Mosques [5]

\subsection{Decorative properties of the Safavid period}

In this period, architectures preferred to utilize polychrome tile (Haftar) and mosaic for decoration. For instance, Mina tile has been widely used all over in Iran [8].

\subsection{The Process of mosque entrance formation}

The general scheme of entrance in early mosques were simple and consisted of one of more doorways. Also, some features were without door [3]. Throughout the second half of first lunar century (Hijri- lunar calendar), the design and decoration of facades has been a significant concept in architectural design. Gradually the entrance position was taken place in a closer location in front of qibla. "In early mosques, entrance was often positioned at the corner of the mosque. Likewise, assessing the court is taken on one of the angles. In what follows, this space was located along the symmetry axes of the courtyard and in front of qibla [15]. The principles and hypothesis utilized in large and grand mosques' entrance design can be listed as follows: 1) Coming into courtyard or nave across the qibla. 2) Firstly, joining to the courtyard next opening to nave and dome (Introverted mosque). 3) Opening to the courtyard either across the symmetry axes or in directions parallel to it (Introverted mosques). 4) Inserting in mosques' internal space with a quiet and calm manner not suddenly and sharply. 5) Addressing the direction divergence between qibla axes and crossing axes or the square linking to the mosque portal in internal space. 6) Assigning or identifying the mosque entrance location for those who are far away [15].

\subsection{The Components of Mosque Entrance}

At the beginning the mosque's internal space was composed of one part: the doorway. However, many features, elements and parts were added up about the gradual chronological dating of different historical levels. Besides, 
design techniques and its connection to adjacent surface, decoration and etc. were developed simultaneously.

1) Frontage (Jelokhan)

2) The basin in the middle of courtyard

3) Portal

4) Doorway

5) Vestibule

6) Passageway

7) Iwan (Veranda) [14], [15].

\subsection{The Entrance Elements of Mosques}

The entrance space not only has identified as an element of a unified architectural design (mosque) but also it is composed of various components and elements. The entrance elements of mosques can put forward as follows:

1) Over door

2) Door (entrance door)

3) Door Knocker

4) Threshold

5) Platform

6) Minaret

7) Mazaneh

8) Font

9) The watch [1] [14], [15].

\section{The Numerical and Statistical Analysis of the Safavid Mosques in Tabriz}

In this section we prepare analytical and descriptive techniques as a tool to compare the Safavid mosques in Tabriz. Furthermore, this analysis is carried on in terms of mosque entrance comparison. With reference to previous sections, we aim to provide a sense of analogy in the entrance structure from two numerical and statistical aspects. Four mosques from the Safavid period in Tabriz has been selected for this study. The mosques are called as Saheb Ol-Amr, Zahiriyeh, Maghsoudiyeh Square and Haj Safar Ali. As a first step a brief explanation of each structure is represented. The following step begins by numerical and geometrical comparison of their entrance features. The last step is related to statistical analysis.

Saheb Ol-Amr Mosque: This mosque is one of the ancient and glorious mosques in Tabriz. This mosque was located in the central part of Tabriz. This mosque was built by King Tahmaseb the first (I) but destructed completely by Osman soldiers. Katib Chalabi the author of "Jahan-Nama" described that:" In the eastern side of Saheb Ol-Amr square which was linked to Grand Soltan Hasan mosque, there was an adorned mosque. Since this building was belonging to King Tahmaseb the first (I), Osman soldiers destroyed the whole mosque." After retreating of Osman, the mosque was reconstructed by Azerbaijan minister "Mirza Mohammad Ibrahim "in the same place in Soltan Hossein period. In 1193 (The date is demonstrated in Hijri calendar) Tabriz earthquake, the mosque were strongly damaged, then the mosque was reconstructed again by "Mirza Ali Akbar Khan"(the interpreter of Russian Consulate in Tabriz) and then "Akbariyeh School" was built in one corner of the mosque courtyard. During its reconstruction, the mosque was composed of a dome and two minarets. The data showed that the shape of dome and minaret were different from the other three mentioned mosques. From King Tahmaseb the first (I) reign, only two marble rooms were preserved which is historically important [6].

Zahiriyeh Mosque: In fact, this mosque is located in the western side of Seyyed Hamzeh Tomb. The mosque has been designed with no columns. In the measurement of this structure, its dimension is $20 \times 8$ meter with a great dome. It has been shown that the decoration and inscription on the ceiling is of (Mazhab) type. The mosque has been founded by Zahir-Al-Din, the son of Sadr-Al-Din, Azerbaijan minister in 1087 (Hijri). The Tomb and the school of Seyyed Hamzeh was reconstructed by him. This mosque has an endowment letter and it was reconstructed for the last time in 1297 (Hijri) in Naser-Al -Din Shah reign.

Maghsoudiyeh Square Mosque: The main structure of this mosque is constructed in the Safavid era and composed of three parts. The first section is found in brick vault folded with ten-part arches type. The overlay of dome of this mosque is of trefoil (Galo dar ham) arches scheme. The last part is related to its dressed stone columns and capitals. Throughout history, this mosque was frequently destroyed and suffered from natural disasters like as earthquake and landslide. Fortunately, by the efforts of Tabriz Cultural Heritage, this mosque was reconstructed and rebuilt for three times in 1376, 1384 and 1388 .

Haj Safar Ali Mosque: Haj Safar Ali Mosque is placed in the northern side of Hai Safar Ali School. Explain with more detail, this mosque is settled in Yemen Doozan Bazar, in the southwest side of Chay-Kenar Boulevard in Darayi street intersection in Tabriz. The mosque was constructed by Haj Safar Ali Khoyi, the famous merchant, in Abbas Mirza regent period, in the same place as that of the initial one. This beautiful and magnificent building with a high dome, is containing minarets which engraved on blue tiles. The cap and some top part of minaret were collapsed in the past. Both eastern and western side of this mosque, has linked the two opposite column-based halls. Each hall can be observed as a distinct mosque. The central mosque ties up these two halls with some wooden windows. When leaving the windows open, all three courts drew a unified mosque. The data carries on the arguments of existing a wall in front of Iwan(Veranda) and dome and positioning mihrab inside this wall. The evidence demonstrates that these elements were added up in the latter era. In other sides of the yard, there exist some rooms for religious science students. This building was assessed the highest extent of symmetry and stability. The reason of this claim is related to the famous flood in 1288 Lunar Hijri. However, more than half space of the mosque was filled by water, fortunately, the mosque was not damaged. Table 1 illustrates the visual forms of these mosques [7].

\subsection{Numerical Analyzing of the entrance in the Sample Mosques}

In this section, we restrict our analysis to specific part of these mosques. Now, we proceed with the numerical analysis of major dimension employed in mosques' entrance.

Saheb Ol-Amr Mosque: The plan proportion and the entrance area for this mosque is measured as follows: 1) the plan area measures about $430.4658 \mathrm{~m}^{2} ; 2$ ) the entrance area measures about $71.2287 \mathrm{~m}^{2}$; and 3) the ratio of entrance area to plan area measures about $0.1655 \mathrm{~m}^{2}$. Figure 2 illustrates this proportions. The components of mosque entrance in terms of shape is average and in terms of scale is categorized as human scale type. This numerical analysis shows that the ratio of depth to width is about 0.59 , the ratio of height to width is 1.87. Also, the depth, height and width are measured as 3.3 , 10.32 and5.5 meter respectively. Table 2 depicts the measures. The elements of mosque entrance are observed as over door, platform, door knocker and door. 
Table1: Name and the figure of the sample mosques in the Safavid Period in Tabriz (References: the authors)
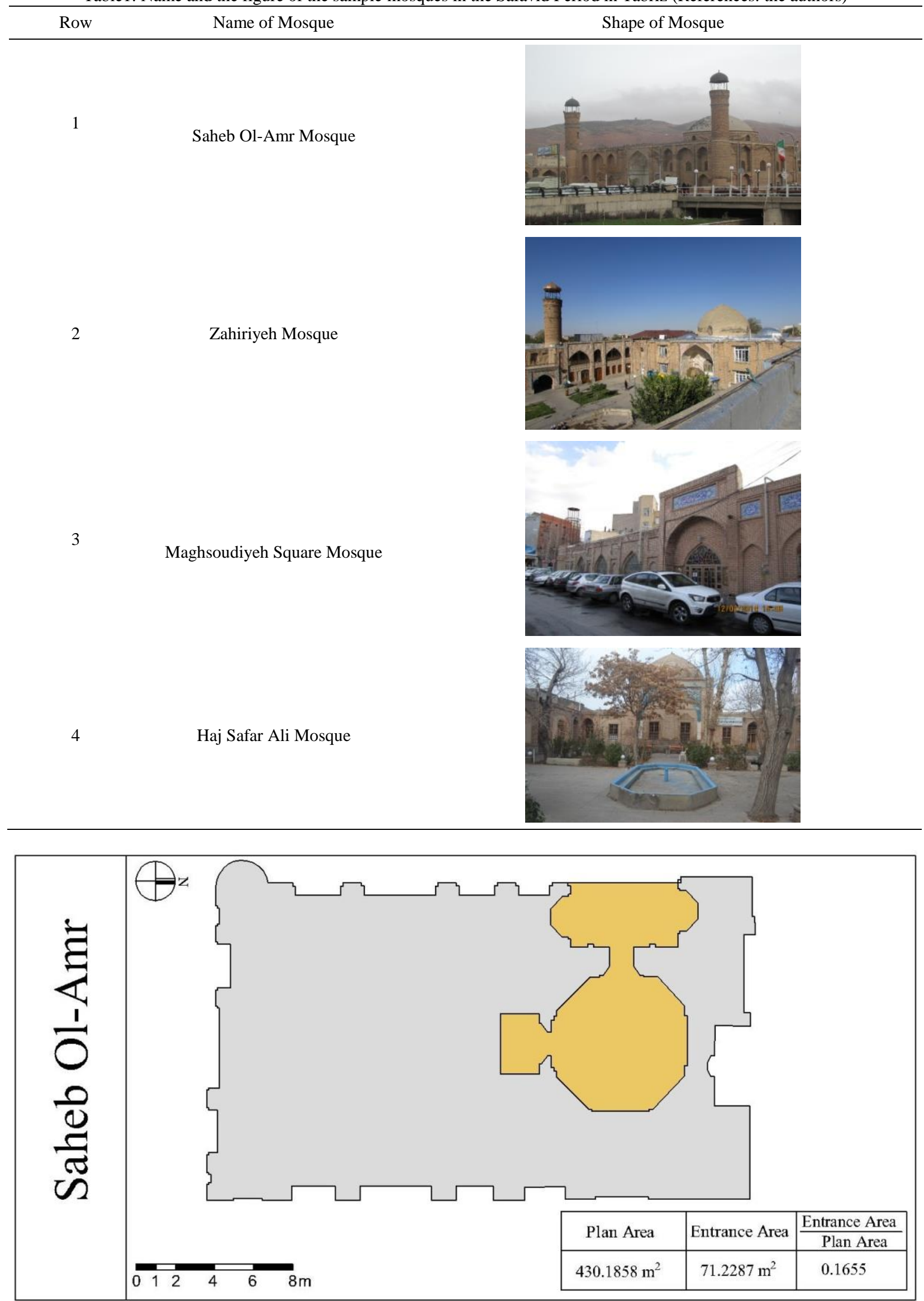

Figure (2): the proportions of plan and Saheb Ol-Amr mosque entrance (References: the authors) 
Table 2: The components of Saheb-Ol Amr mosque entrance (References: the authors)

\begin{tabular}{|c|c|c|c|c|c|c|}
\hline \multicolumn{7}{|c|}{ The proportions of plan and Saheb Ol-Amr mosque entrance } \\
\hline Width b & Height h & Depth $\mathbf{~ d ~}$ & $\mathbf{h} / \mathbf{b}$ & $\mathbf{d} / \mathbf{b}$ & Scale & Form \\
\hline 5.5 & 10.32 & 3.3 & 1.87 & 0.59 & human scale & average \\
\hline
\end{tabular}

Table 3: the elements of Saheb-Ol Amr mosque entrance (References: the authors)

\begin{tabular}{|c|c|c|c|}
\hline \multicolumn{3}{|c|}{ The elements of Saheb-Ol Amr mosque entrance } & Over door \\
\hline door & knocker & platform & $\checkmark$ \\
\hline$\checkmark$ & $\checkmark$ & $\checkmark$ & \\
\hline
\end{tabular}

Table 4: The Characteristics of Saheb-Ol Amr façade (References: the authors)

\begin{tabular}{|c|c|c|c|c|}
\hline \multicolumn{5}{|c|}{ The Characteristics of Saheb-Ol Amr facade } \\
\hline Frontage & Frontage & Doorway & Vestibule & Passageway \\
\hline$\times$ & $\checkmark$ & $\checkmark$ & $\checkmark$ & $\times$ \\
\hline
\end{tabular}

Refer to Table 3 the characteristics of facade is listed as pre-vault, doorway and vestibule and shown in Table 4.

Zahiriyeh Mosque: The plan proportion and the entrance area for this mosque is measured as follows: 1) the plan area measures about $1000.9410 \mathrm{~m}^{2} ; 2$ ) the entrance area measures about $64.0035 \mathrm{~m}^{2}$; and 3) the ratio of entrance area to plan area measures about $0.1638 \mathrm{~m}^{2}$. Figure 3 declares this proportions. The components of mosque entrance in terms of shape is average and in terms of scale is classified as human scale type. This numerical analysis shows that the ratio of depth to width is about 0.53 , the ratio of height to width is 1.78. Also, the depth, height and width are measured as 2.34 , 7.75 and 4.35 meter respectively. Table 5 summarizes the measures. The elements of mosque entrance are observed as over door, platform, door knocker and door. Table 6 states the data. The characteristics of facade is listed as atrium, passageway, pre-vault, doorway and vestibule and shown in Table 7.
Maghsoudiyeh Square Mosque: The plan proportion and the entrance area for this mosque is measured as follows: 1) the plan area measures about $910.3950 \mathrm{~m}^{2} ; 2$ ) the entrance area measures about $166.1398 \mathrm{~m}^{2 ;}$ and 3) the ratio of entrance area to plan area measures about $0.1824 \mathrm{~m}^{2}$. Figure 4 affirms this proportions.

The components of mosque entrance in terms of shape is elongated (wide) and in terms of scale is categorized as human scale type. This numerical analysis shows that the ratio of depth to width is about 0.14 , the ratio of height to width is 1.26. Also, the depth, height and width are measured as 0.75 , 6.59 and 5.21 meter respectively. Table 8 portrays the analysis. The element of this mosque entrance is composed of a door. Table 9 expresses this element. The characteristics of facade is listed pre-vault and doorway and recognized in Table 10.

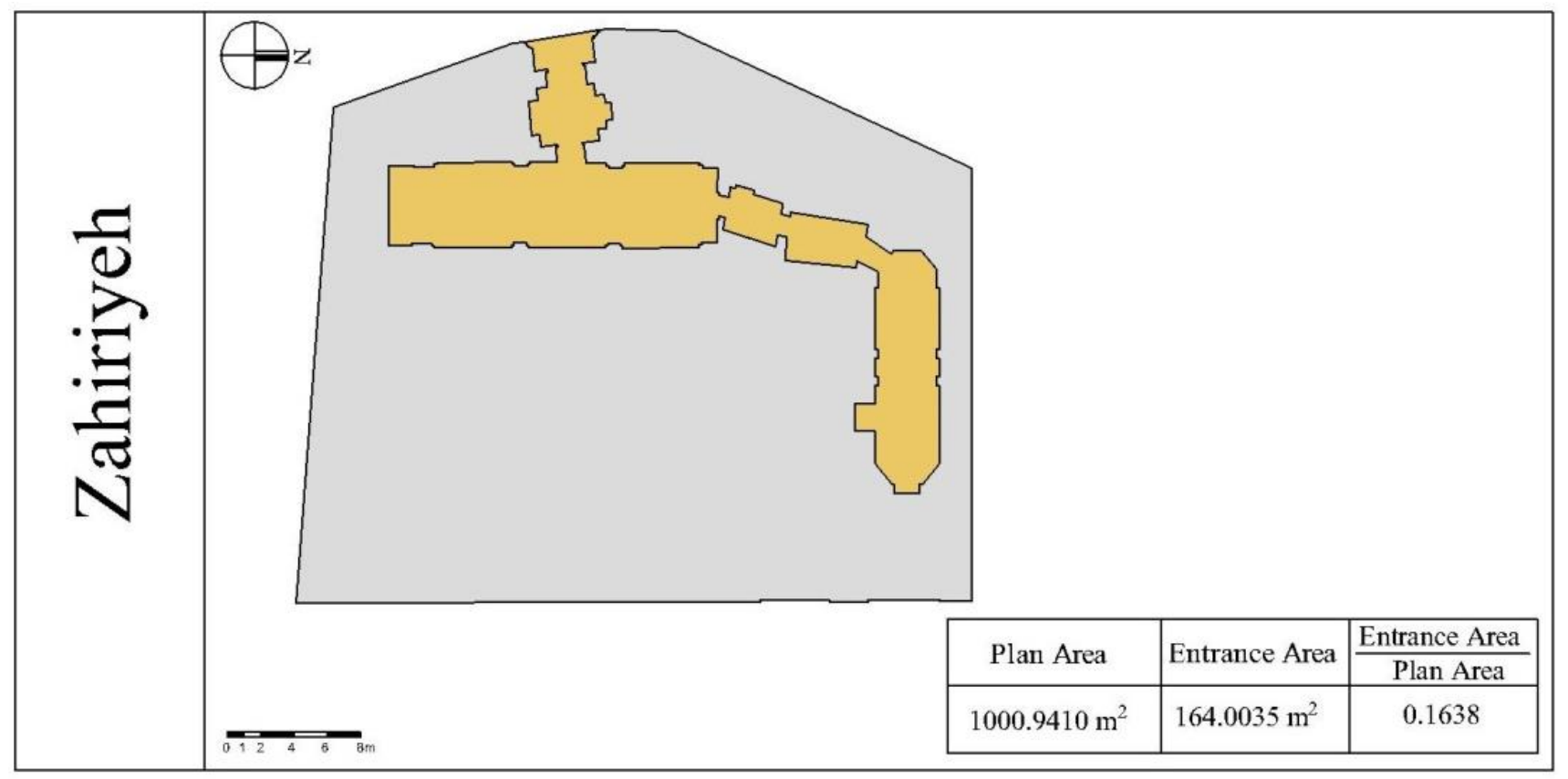

Figure 3: The proportions of plan and Zahiriyeh mosque entrance (References: the authors)

Table 5: The components of Zahiriyeh mosque entrance (References: the authors)

\begin{tabular}{|c|c|c|c|c|c|c|}
\hline \multicolumn{7}{|c|}{ The components of Zahiriyeh mosque entrance } \\
\hline Width b & Height $\mathbf{~}$ & Depth $\mathbf{d}$ & $\mathbf{h} / \mathbf{b}$ & $\mathbf{d} / \mathbf{b}$ & scale & form \\
\hline 4.35 & 7.75 & 2.34 & 1.78 & 0.53 & Human scale & medium \\
\hline
\end{tabular}


Table 6: The elements of Zahiriyeh Mosque (References: the authors)

\begin{tabular}{|c|c|c|c|}
\hline \multicolumn{3}{|c|}{ The elements of Zahiriyeh Mosque } & Over door \\
\hline Door & Knocker & Platform & $\checkmark$ \\
\hline$\checkmark$ & $\checkmark$ & $\checkmark$ & $\checkmark$ \\
\hline
\end{tabular}

Table 7: The Characteristics of Zhriyeh Mosque façade (References: the authors)

\begin{tabular}{|c|c|c|c|c|c|}
\hline \multicolumn{7}{|c|}{ The Characteristics of Zhriyeh Mosque facade } \\
\hline frontage & frontage & doorway & vestibule & passageway & iwan \\
\hline$\times$ & $\checkmark$ & $\checkmark$ & $\checkmark$ & $\checkmark$ & $\checkmark$ \\
\hline
\end{tabular}

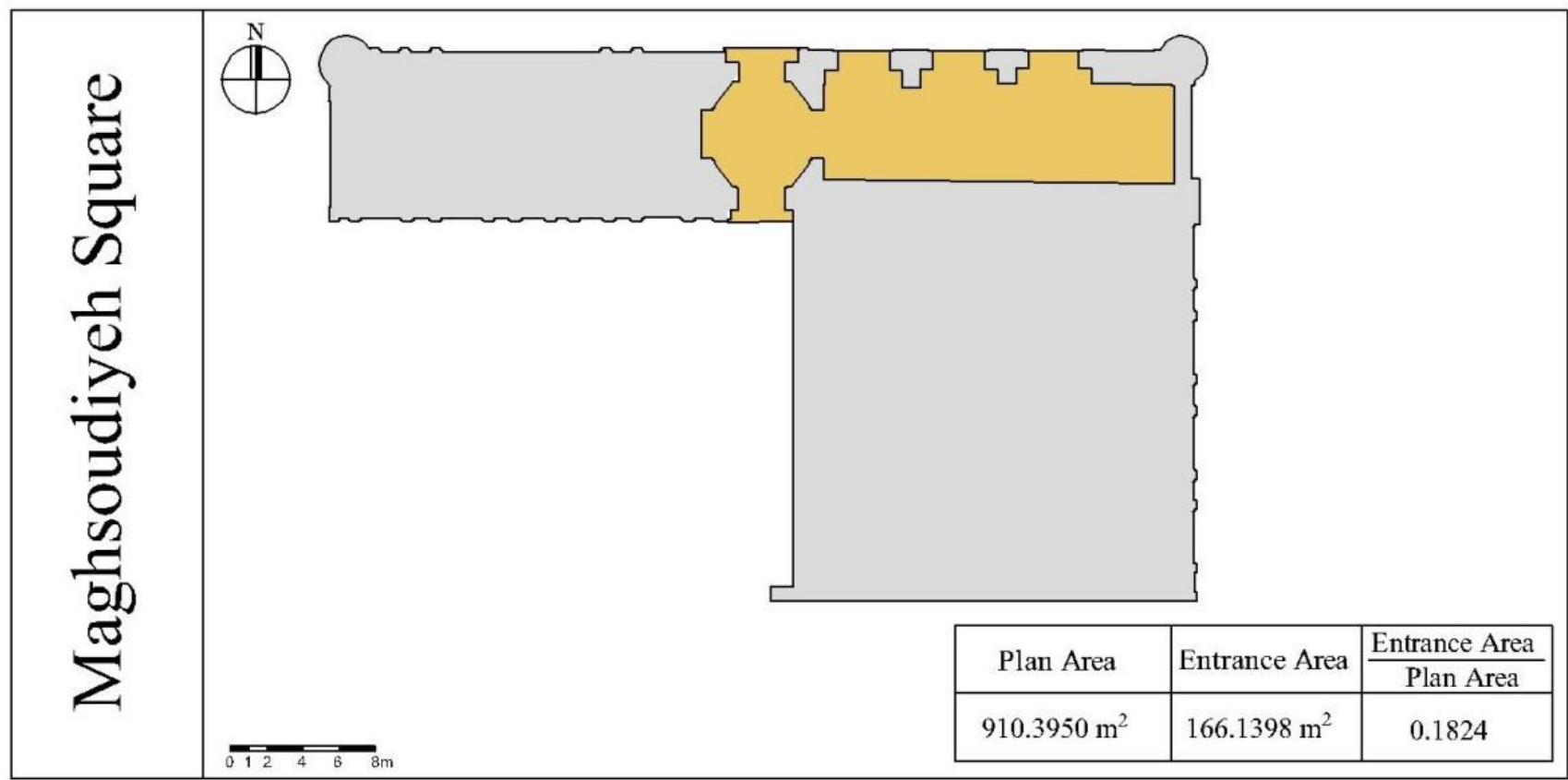

Figure 4: the proportions of plan and Maghsoudiyeh Square mosque entrance (References: the authors)

Table 8: The components of Maghsoudiyeh Square mosque entrance (References: the authors)

\begin{tabular}{|c|c|c|c|c|c|c|}
\hline \multicolumn{7}{|c|}{ The components of Maghsoudiyeh Square mosque entrance } \\
\hline Width b & Height h & Depth d & h/b & d/b & Scale & Form \\
\hline 5.21 & 6.59 & 0.75 & 1.26 & 0.14 & Human scale & Wide \\
\hline
\end{tabular}

Table 9: The entrance elements of Maghsoudiyeh Square Mosque (References: the authors)

\begin{tabular}{|c|c|c|c|}
\hline \multicolumn{3}{|c|}{ The entrance elements of Maghsoudiyeh Square Mosque } \\
\hline Door & Knocker & Platform & Over door \\
\hline$\checkmark$ & $\times$ & $\times$ & $\times$ \\
\hline
\end{tabular}

Table 10: The Characteristics of Maghsoudiyeh Square Mosque façade (References: the authors)

\begin{tabular}{|c|c|c|c|c|c|}
\hline \multicolumn{7}{|c|}{ The Characteristics of Maghsoudiyeh Square Mosque facade } \\
\hline Frontage & Frontage & Doorway & Vestibule & Passageway & Iwan \\
\hline$\times$ & $\times$ & $\checkmark$ & $\checkmark$ & & $\times$ \\
\hline
\end{tabular}

Haj Safar Ali Mosque: The plan proportion and the entrance area for this mosque is measured as follows: 1) the plan area measures about $966.2616 \mathrm{~m}^{2}$; 2) the entrance area measures about $107.9702 \mathrm{~m}^{2}$; and 3 ) the ratio of entrance area to plan area measures about $0.1114 \mathrm{~m}^{2}$. Figure 5 depicts these proportions. The components of mosque entrance in terms of shape is tall (elevated) and in terms of scale is classified as human scale type. This numerical analysis shows that the ratio of depth to width is about 0.13 , the ratio of height to width is 2.66. Also, the depth, height and width are measured as 0.25 , 4.79 and 1.80 meter respectively. Table 11 portrays the analysis. The elements of mosque entrance are observed as door knocker and door. Table 12 states the data. The characteristics of facade is listed as atrium, passageway, prevault, doorway and vestibule. Table 13 recognizes these data.

\subsection{Statistical Analyzing of the entrance in the Sample Mosques}

Throughout the Safavid era, Iranian old architecture style was completely developed. Top of all, the shape and materials were taken into account in building designs. The Safavid structures like as mosques, schools, inn and caravanserai are occasionally founded in terms of four-vestibules. Another prosper of this period, is employing polychrome tiles and Mosaic for decoration. As further elaboration on this feature, all parts of religious building, like domes, Iwan (Veranda), arches, over doors and especially minarets were gently 
dressed by tiles. Calligraphy and inscription has been a significant concept in religious buildings decoration. However, this drawing and decoration was enriched by Sols, Naskh and Nastaliq. Likewise, tiling under the domes and mosque's facades carries out the main characteristic of this architecture. The delicate combination of colors, elegance and beauty in these structures engender a natural affinity in the observer. In order to stress on this architecture in addition to numerical analysis, the statistical analysis has been performed too. To address this issue, the shape, entrance elements and characteristic of mosques facades in the Safavid period were more analyzed. Expert choice (version 11) software was employed to determine the importance of these factors separately. From the importance attitude, as the data and analyses detect, the shape achieves the coefficient of 0.36 in mosques' entrance designs. Figure 6 draws the assessed coefficient respectively. From the aspect of shape analysis, Saheb-Ol Amr is located in first place. The second place is assigned to Zahiriyeh Mosque and the rest places belongs to Haj Safar Ali and Maghsoudiyeh Square mosques. Investigation of entrance elements present the ratio of 0.31 in this survey. Again Saheb-Ol Amr has been ranked as the first one. The rest rows are assigned to Zahiriyeh, Haj Safar Ali and Maghsoudiyeh Square mosques, respectively. The ratio of
0.35 shows the importance of characteristics of facade. This illustration draws Haj Safar Ali mosque in the first place and replaces Zahiriyeh, Saheb Al- Amr and Maghsoudiyeh Square mosques in next rows. Figure 7 demonstrates these ranking. In order to analyze the differences among the sample mosques' facade from the larger scale point view, a pair-wise comparison is performed too. This pair-wise comparison is classified into three groups. Saheb-Ol Amr and Zahiriyeh, Saheb-Ol Amr and Maghsoudiyeh and Saheb-Ol Amr and Haj Safar Ali. Through Figure 8 we know that Saheb-Ol Amr is dominated Zahiriyeh in terms of the elements, while the characteristics of Zahiriyeh can prevail the other mosque. Overall, Zahiriyeh employs high potential compared with its pair, Saheb -Ol Amr. From Figure 9, we can also see that Saheb-Ol Amr mosque is higher that the Maghsoudiyeh mosque in all factors employed in this study. This indicates that Saheb-Ol Amr mosque has made great rank from the facade perspective.

Looking at the Figure 10, we find that Haj Safar Ali mosque has the higher situation only in terms of facade characteristics. Also, it can be seen that in two other factors, Saheb-Ol Amr were nearly in a high level which indicated that the work on this facade had made great design.

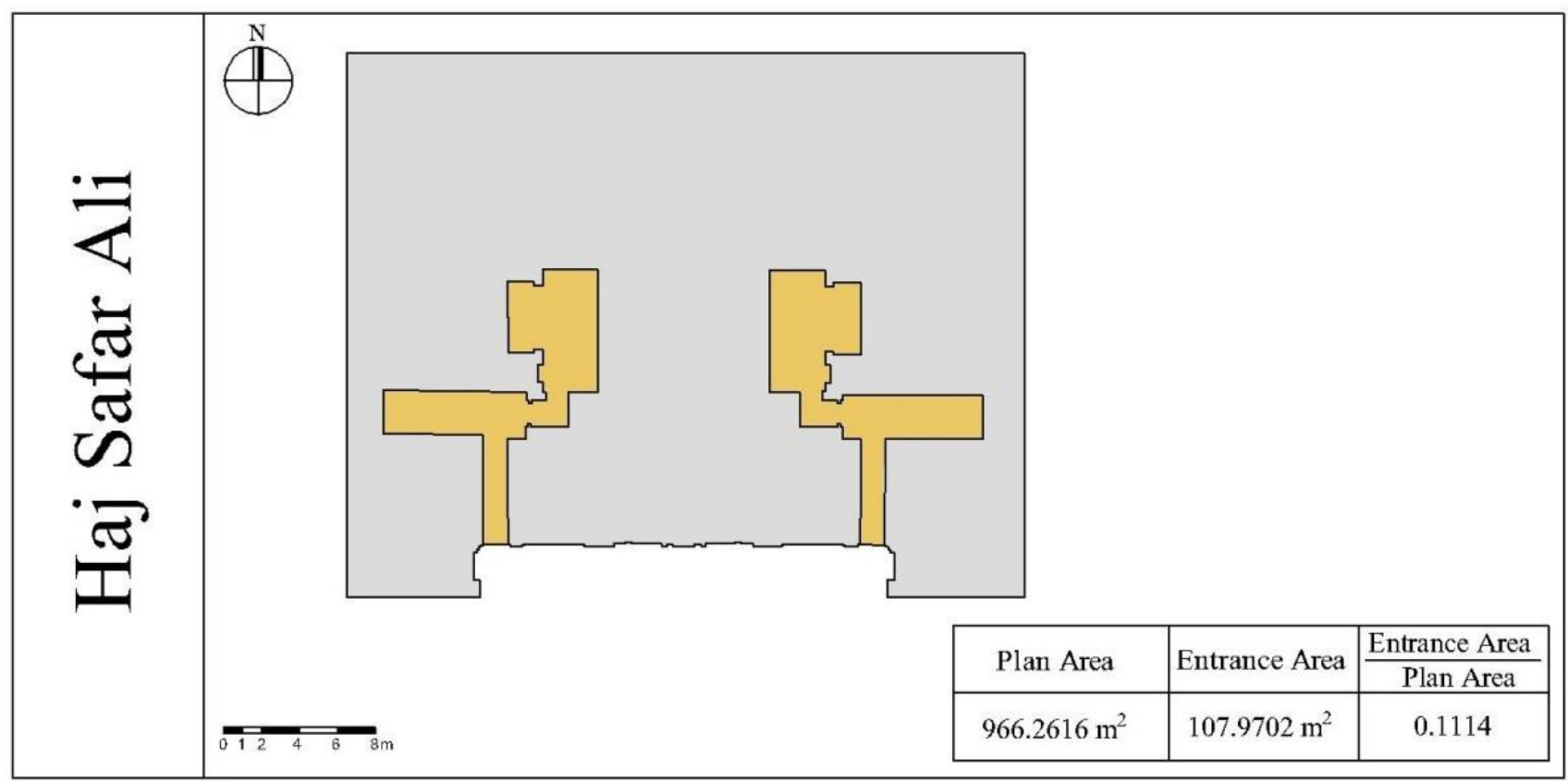

Figure 5: The plan proportions and entrance area in Haj Safar Ali Mosques (References: the authors)

Table 11: The components of Haj Safar Ali mosque entrance (References: the authors)

\begin{tabular}{|c|c|c|c|c|c|c|}
\hline \multicolumn{7}{|c|}{ The components of Haj Safar Ali mosque entrance } \\
\hline Width b & Height $\mathbf{h}$ & Depth $\mathbf{d}$ & $\mathbf{h} / \mathbf{b}$ & $\mathbf{d} / \mathbf{b}$ & Scale & Form \\
\hline 1.80 & 4.79 & 0.25 & 2.66 & 0.13 & Human scale & Tall \\
\hline
\end{tabular}

Table 12: The entrance elements Haj Safar Ali Mosque (References: the authors)

\begin{tabular}{|c|c|c|c|}
\hline \multicolumn{3}{|c|}{ The entrance elements Haj Safar Ali Mosque } \\
\hline Door & Knocker & Platform & Over door \\
\hline$\checkmark$ & $\checkmark$ & $\times$ & $\times$ \\
\hline
\end{tabular}

Table 13: The Characteristics of Haj Safar Ali Mosque façade (References: the authors)

\begin{tabular}{|c|c|c|c|c|c|}
\hline \multicolumn{5}{|c|}{ The Characteristics of Haj Safar Ali Mosque facade } \\
\hline Frontage & Frontage & Doorway & Vestibule & Passageway & Iwan \\
\hline$\times$ & $\checkmark$ & $\checkmark$ & $\checkmark$ & $\checkmark$ & $\checkmark$ \\
\hline
\end{tabular}



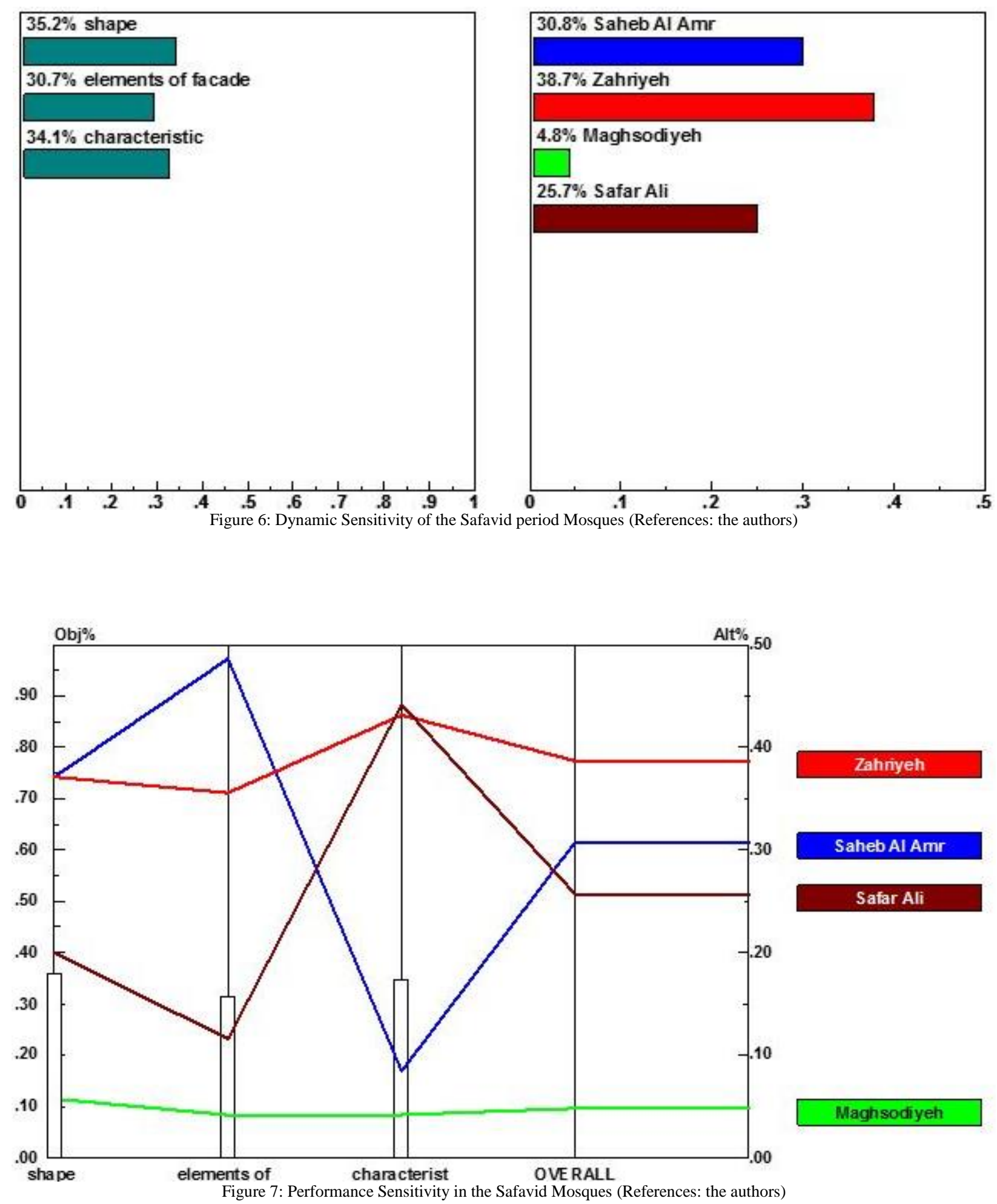

To sum up, as the statistical analysis presents there exist various aspect for ranking the sampled mosques. Although they all are glorious and eye-catching, but Saheb-Ol Amr is superior to other alternatives in advance. 


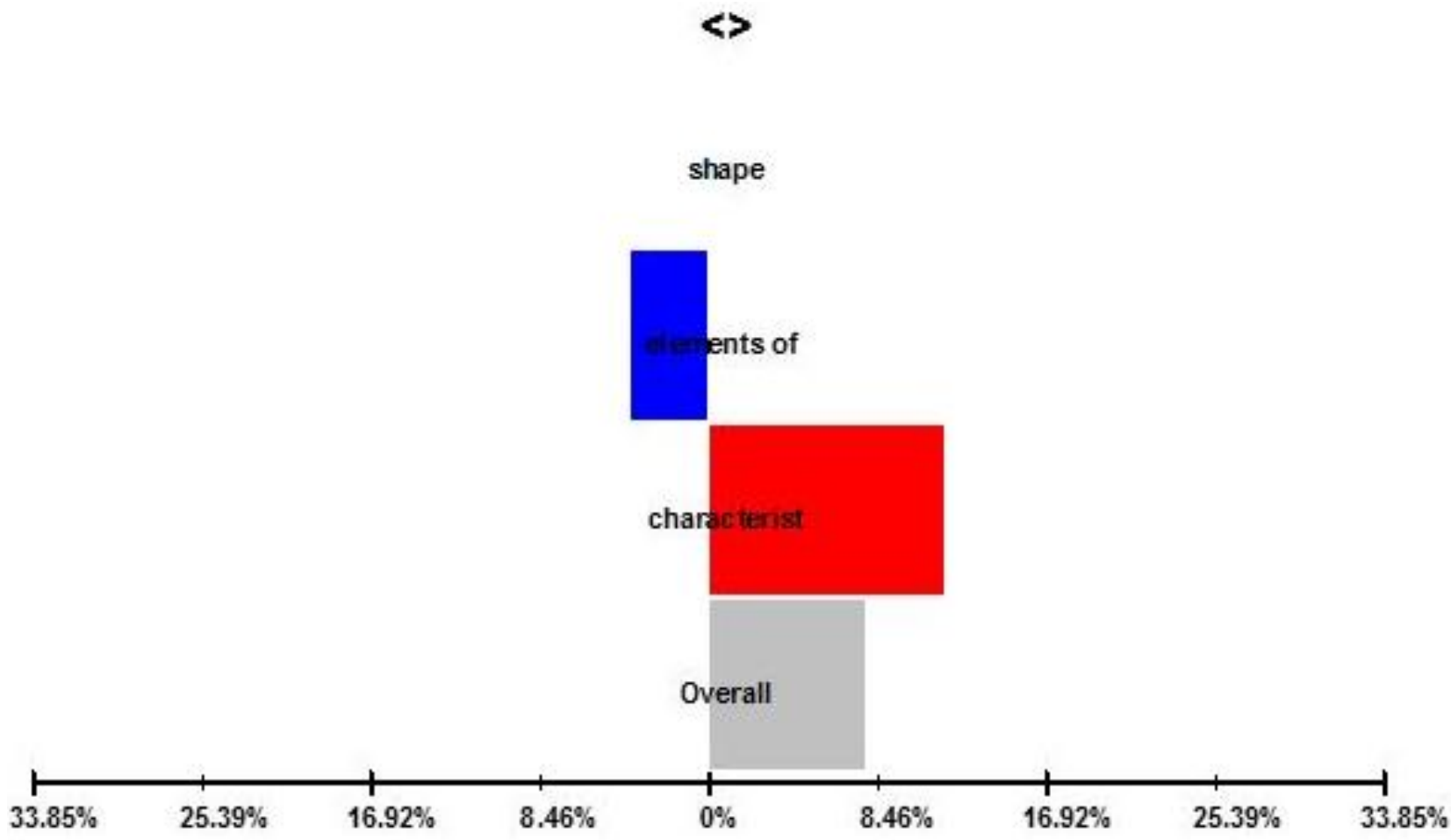

Figure (8): weighted head to head between Saheb-Ol Amr and Zahiriyeh-References:the authors

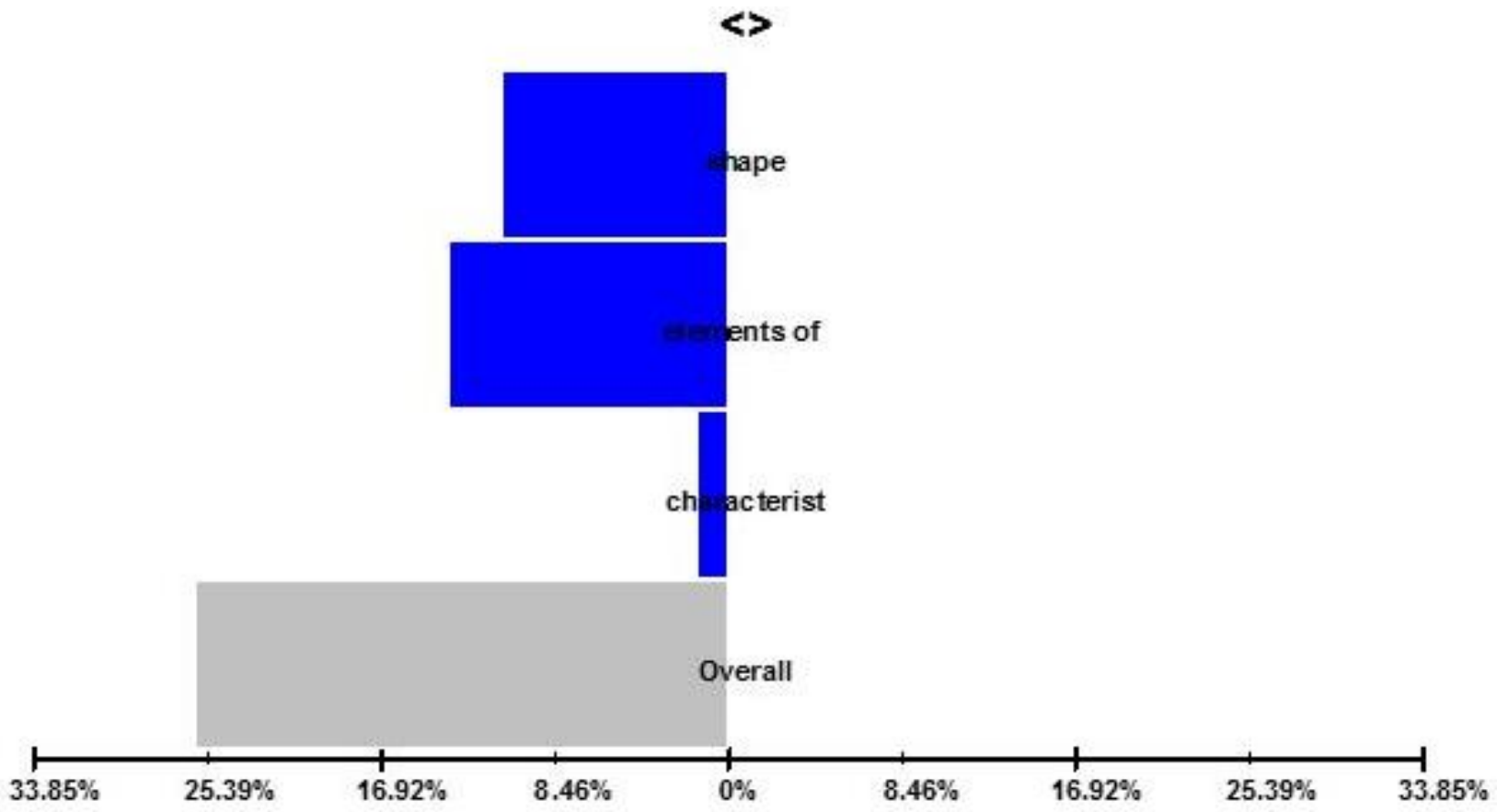

Figure 9: Weighted head to head between Saheb-Ol Amr and Maghsoudiyeh (References: the authors) 


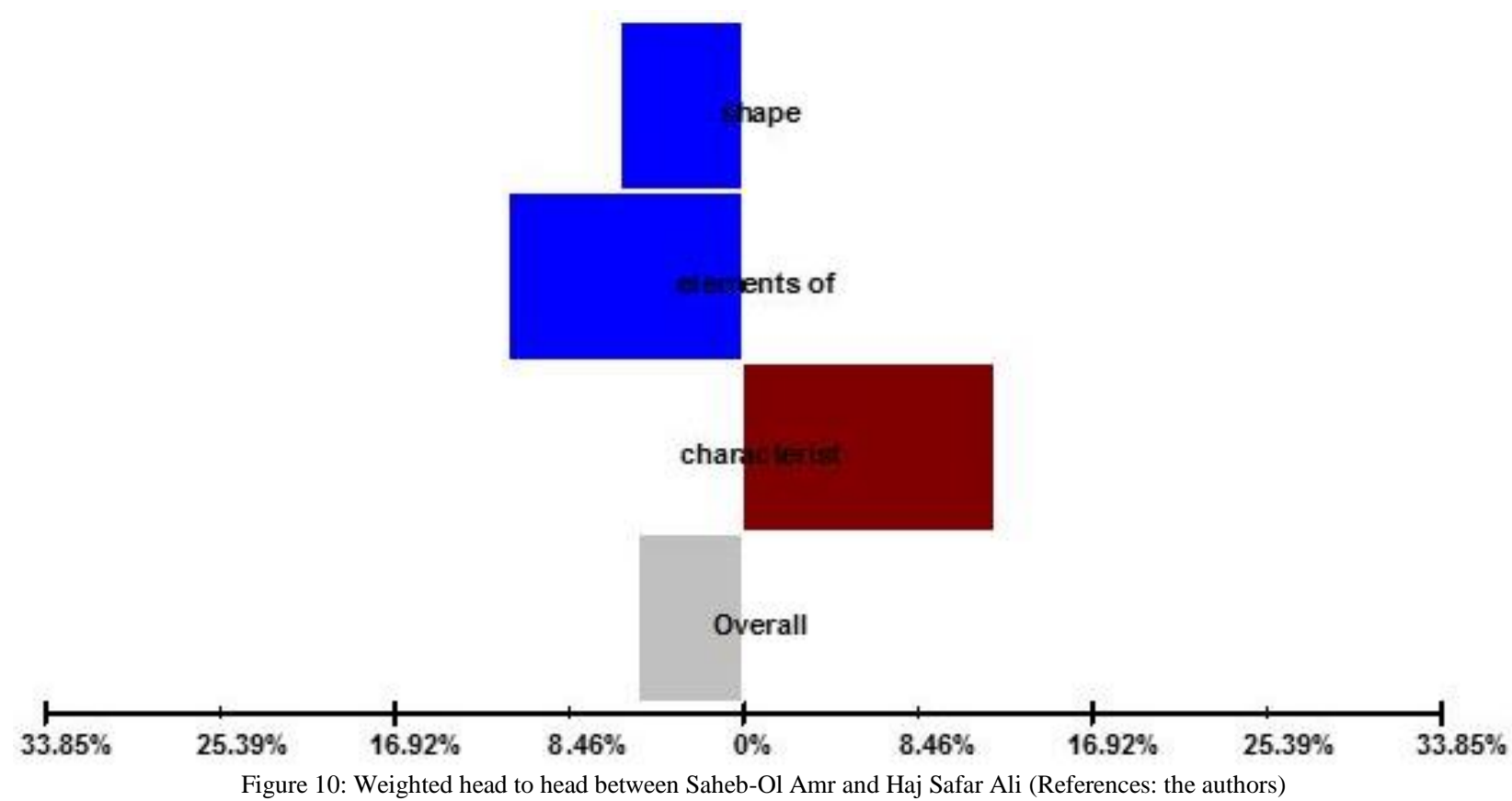

\section{Conclusion}

This study explained that the Safavid architecture was so experienced and skillful in mosque's facade design. The glory and the greatness of these structures is the dominating feature in the Safavid composition. Among the selected mosques in the Safavid period in Tabriz, Saheb Ol-Amr mosque was acknowledged as the most important one in the Safavid era. The findings showed that the largest entrance in terms of mosque plan are related to Maghsoudiyeh mosque and the smallest is occupied by Haj Safar Ali. It appears from observation that the Safavid mosques in Tabriz has no element as pre-court or "Frontage (Jelokhan)". Quite the opposite, in all four mosques the scale has been classified in terms of human scale. In terms of shape, Saheb Al -Amr and Zahiriyeh has been sorted as average, Maghsodiyeh Square mosque is tabulated as tall(elevated) and Haj Safar Ali is arranged as a long(elongated) one. Taking a closer look to mosque's entrance components, the study revealed that Maghsoudiyeh mosque has the greatest ratio of entrance area to plan area, and Haj Safar Ali mosque is the smallest among the sample mosques. It should be recognized that in elements of mosque entrance, Saheb Ol-Amr and Zahiriyeh mosques accommodate the four elements: over door, platform, doorknocker and door. Haj Safar Ali mosque contains doorknocker and door. Maghsodiyeh Square mosque has been reviewed by an element: a door. The numerical results of facade characteristics noticed that Haj Safar Ali and Zahiriyeh mosques include pre-vault, doorway, vestibule, passageway, and atrium. Saheb Ol-Amr is formed by pre-vault, doorway and vestibule. Finally, Maghsodiyeh Square mosque is confirmed by pre-vault and doorway. The statistical analysis demonstrates the importance of each factors considered in facade design. The shape of entrance is located in the first place with the ratio of $36 \%$, the following place are occupied by characteristics of entrance $(35 \%)$ and elements of the facades with the coefficient of $31 \%$. Each aspect gives various results. Saheb $\mathrm{Al} \mathrm{Amr}$ Mosque is in the first place from the point of the shape and elements. On the other hand, Haj Safar Ali assessed the first location from the characteristics point of view. While, Saheb Al Amr Mosque has been achieved the third place from this view. Both numerical and statistical analysis displayed that Saheb-Ol Amr mosque is superior than those of the other mosques in the sample.

\section{Acknowledgment}

This paper is derived from $\mathrm{PhD}$ thesis entitled as" Təbriz şəhərinin orta əsr məscidlərinin memarlığı" under supervision of Professor Jafar Giyasi.

\section{Ethical issue}

Authors are aware of, and comply with, best practice in publication ethics specifically with regard to authorship (avoidance of guest authorship), dual submission, manipulation of figures, competing interests and compliance with policies on research ethics. Authors adhere to publication requirements that submitted work is original and has not been published elsewhere in any language.

\section{Competing interests}

The authors declare that there is no conflict of interest that would prejudice the impartiality of this scientific work.

\section{Authors' contribution}

All authors of this study have a complete contribution for data collection, data analyses and manuscript writing.

\section{References}

[1] Ardalan, Nader., Bakhtiar, Laleh., (1379), "The Sense of Unity: The Sufi Tradition in Persian architecture", Translated in Persian by: Hamid Shahrokhi, Tehran: Khak Publication.

[2] Attarian, Koorosh., Momeni, Kooreoh, Masoudi, Zohreh., (2015), "The study of courtyard proportions in the Safavid Mosques of Isfahan", Motaleate Tatbighi Honar, Vol.5, No.10, 67-81, (In Persian)

[3] Ebne Raste., (1368), "Alag Al Nafise Va Valiye Ketab al Boldan", Translated by: Hussain Gare Chanloo, Tehran: Amir Kabir Publication. (In Arabic).

[4] Hillenbrand, Robert, (1383), "Islamic architecture: Form, Function, and meaning", Translated by: Bager Ayatollahzadeye Shirazi, Tehran, Rozaneh Publication, (In Persian).

[5] Khazaee, Maryam., (2015), "Influence of the Timurd Architecture on the Safavid and Mughal Mosques in India", Thesis Submitted in Fulfilment of the Requirements for the Degree of Doctoral 
Philosophy (PhD), Faculty of Built Environment, Malesia, University of Kuala- Lampur.

[6] Motafakker Azad, Maryam, Zogi, Leila. (1395), "Tabriz Quran and Inscription (Kitabat)Museum; Quranic works treasury (Sahib Al Amr Mosque)", The Proceeding of International Conference On Oriental Studies, Persian Literature and History, Erevan State University, Erevan, Armenia.

[7] Niknam, Laleh., Zogi., Faribor., (1396), "Tabriz Dar Gozare Tarikh (Negahi be Tarikhe Azerbaijan)", Yaran Publication, (In Persian).

[8] Pirniya, Mohammad Karim. (1380), "Sabk Shenasi e Memari e Irani": Edited by: Golam Hussein Memarian, Tehran, Pajumand Publication. (In Persian).

[9] Pope, Arthur Upham. (1965), "Iranian Architecture: the triumph of form and color", George Braziller Publication.

[10] Pope, Arthur Upham., (1382)," Iranian Architecture", Translated by: Gholam Hossein Sadri- Afshari, Tehran, Akhtaran Ketab Publication, (In Persian).

[11] Poormand ,Hasanali., Yarali, Zahra., Afhami, Reza., Abbasi, Pouriya., (2014), "A Study on Proportions of Entrance Facade of Sheikh Lotfolah, Ja me Abbasi, Hakim Mosques and ChaharBagh School in Isfahan", Journal of Architecture and Urban Planning, Vol.6, No.12,164-153

[12] Rafooneh, Mokhtar Shahi Sani., (2009), “An Inquiry into Iranian Architecture Manifestation of Identity, Symbolism, and Power in the Safavid's Public Buildings", Submitted to the Institute of Graduate Studies and Research in partial fulfillment of the requirements for the Degree of Doctoral Philosophy in Architecture, Eastern Mediterranean University, North Cyprus.

[13] Ramezan Jamaat, Mina, Neyestani, Javad., (1389), "The Manifestations of Modernity and Tradition in the Entrance Spaces of Houses in Tehran in Qajar Era", Honar- Ha-ye Ziba Memari Va Shahrsazi, Vol.2, No.44, 65-76. (In Persian).

[14] Sattari Sarbangoli, Hasan, (1379), "Manifestation of Mysticism, Light and Color in Mosque Architecture", Proceeding of the Second International Conference in Mosque Architecture, Tehran Art University, 239-450.

[15] Soltanzadeh, Hussain, (1372), "Entry Spaces in traditional architecture of Iran", Tehran, Cultural Research Bureau. (In Persian)

[16]] Stierlin, H., Stierlin, A., (2002), "Islamic art and architecture: From Isfahan to the Taj Mahal", Thames \& Hudson Publication.

[17] Vaez Zade Asadi, Negin. Raisi, Tahereh., (1393), "Investigation of Physical Factors on formation of Spiritual Sense in Mosques", The ninth $\left(9^{\text {th }}\right)$ Symposium on Advances in Science \& Technology, Mashhad, Iran, Page 2. 